\title{
Resenha - Buracos negros: palestras da BBC Reith Lectures
}

\author{
A review of Black Holes: the BBC Reith Lectures \\ Jair Lúcio Prados Ribeiro*1 \\ ${ }^{1}$ Instituto de Química, Universidade de Brasília, Brasília, DF, Brasil
}

Recebido em 06 de Fevereiro de 2017. Aceito em 26 de Fevereiro de 2017

\begin{abstract}
Apresenta-se uma resenha crítica do livro Buracos negros: palestras da BBC Reith Lectures, de autoria de Stephen Hawking. O livro é a transcrição de duas palestras que o autor ministrou em 2016 para a BBC Radio 4 e pode ser entendido uma introdução sobre o tema, adequada para leigos e estudantes de ensino médio.

Palavras-chave: Stephen Hawking, buraco negro, divulgação científica
\end{abstract}

A critical review of Stephen Hawking's Black Holes: the BBC Reith Lectures is presented. The book is a transcript of two lectures that the author gave in 2016 to BBC Radio 4 and can be understood as an introduction on the subject, suitable for laymen and high school students.

Keywords: Stephen Hawking, black hole, science communication

\section{Resenha}

A carreira de divulgador científico de Stephen Hawking se iniciou nos anos 1970. Ferguson [1] relata que cresceu nessa época o interesse do público pelo tema dos buracos negros, fazendo com que artigos em revistas e programas de televisão já viessem a contar a marcante trajetória pessoal e acadêmica de Hawking. Para a autora, entretanto, a publicação de Uma breve história do tempo [2] em 1988 elevou Hawking à categoria de um ídolo, com atenção só comparável àquela usualmente concedida a esportistas e músicos, e levando virtualmente todas as publicações do mundo a apresentarem tanto seu perfil quanto seu ideário [1].

A obra de divulgação mais recente de Hawking é o livro aqui resenhado, Buracos negros: palestras da BBC Reith Lectures [3] (figura 1), publicado em 2016 na Inglaterra, o qual ganhou uma edição brasileira em 2017. O curto livro (extensão de apenas 64 páginas) foi produzido a partir da transcrição de duas palestras que Hawking proferiu para a estação inglesa BBC Radio 4, cujos áudios estão disponíveis na íntegra na página da instituição [4].

Sir John Reith foi o primeiro diretor-geral do conglomerado de mídia britânico BBC. Em 1948, ele iniciou um programa de periodicidade anual, intitulado The $B B C$ Reith Lectures, no qual um pensador eminente era convidado a apresentar suas ideias para o público através de transmissões radiofônicas. Com o advento da internet, a $\mathrm{BBC}$ disponibilizou o arquivo integral de tais palestras para o público [5]. Entre os palestrantes, figuram o filósofo Bertrand Russell (1948), o físico Robert Oppe-

*Endereço de correspondência: jairlucio@gmail.com nheimer (1953), o economista John Kenneth Galbraith (1966), o geneticista Steve Jones (1991) e o cosmólogo Martin Rees (2010).

O livro em questão lida com um tema recorrente na carreira de divulgador científica de Hawking, os buracos negros, mas apresenta, a nosso ver, uma menor densidade teórica do que a apresentada em outras obras do autor, como $O$ universo numa casca de noz [6]. Esse caráter menos exigente e a pequena extensão do texto permite que o livro seja entendido como uma leitura introdutória sobre o tema, atraente para leigos.

As duas palestras conferidas por Hawking para a BBC foram transcritas para a obra: Buracos negros não têm cabelo? e Buracos negros não são tão negros quanto se diz. As palestras foram ministradas ao vivo para uma plateia de ouvintes, dentre os quais se encontravam cientistas britânicos, e após a exposição inicial, seguiu-se uma rodada de perguntas (cujas respostas, como ressaltado pelo editor, foram formuladas de antemão, dadas as reconhecidas dificuldades motoras de Hawking). Cabe frisar, entretanto, que o livro apresenta apenas as transcrições das palestras em si, deixando ausentes as rodadas de perguntas. A nosso ver, tal opção empobrece o conteúdo da obra, na medida em que Hawking aproveita tais perguntas para detalhar ou elucidar algumas passagens do texto principal.

O texto de Hawking é acompanhado por um conjunto de notas explicativas, elaboradas por David Shukman, editor de ciências da BBC News. Tais notas têm o caráter de notas de rodapé, mas ao contrário, se encontram propositalmente entremeadas com o texto. Tal escolha, a nosso ver, facilita o entendimento dos termos mais 
complexos para os leitores leigos, apesar de, ao mesmo tempo, prejudicar um pouco a fluidez da leitura.

As ilustrações produzidas pelo estúdio Cognitive para o livro são apresentadas na forma de desenhos à mão, com intencional comicidade: por exemplo, a detecção de partículas virtuais é feita por um nariz de porco, enquanto o físico Werner Heisenberg é representado por uma popular caricatura do ator Bryan Cranston, o qual interpretava um professor de química que se torna traficante no seriado de televisão Breaking Bad, vindo o personagem a adotar o pseudônimo de Heisenberg nas suas transações comerciais de metanfetamina. Já os raios gama são associados ao super-herói Hulk, o qual teria surgido quando o cientista Bruce Banner foi exposto a doses maciças de tal radiação.

$\mathrm{Na}$ transcrição da primeira palestra, chama a atenção o fato de Hawking não exatamente responder à pergunta "buracos negros não têm cabelo?", acreditamos que de forma intencional, em uma estratégia para "manter o suspense", ou seja, reativar o interesse para a segunda palestra, na qual ele então explica o significado da expressão: não se pode dizer o que há no interior do buraco negro ao observá-lo de fora. Nessa palestra, Hawking apresenta um histórico sobre o conceito dos buracos negros, dando destaque especial às contribuições de John Wheeler. Ele alude também aos seminais artigos de Robert Oppenheimer, elaborados em coautoria com seus alunos George Volkoff [7] e Hartland Snyder [8], os quais terminaram por demonstrar que estrelas de grande massa não seriam sustentadas por sua pressão interna, produzindo seu eventual colapso gravitacional em um ponto de densidade infinita - uma singularidade.

Hawking destaca que essas singularidades eram conhecidas então por "estrelas congeladas", vindo a expressão buraco negro a ser popularizada a partir do seu uso por John Wheeler em 1967. Hawking defende que o nome se tornou popular devido à aura de mistério que o mesmo conferia às estrelas colapsadas, e destaca ainda a resistência inicial dos franceses ao termo (trou noir), o qual traria conotações pejorativas. A "ausência de cabelo" é atribuída pelo autor também a Wheeler, o qual teria demonstrado que um buraco negro só guarda a massa, estado de rotação (momento angular) e carga das partículas que o compõem - ou seja, o buraco negro não tem cabelos.

O histórico apresentado na primeira palestra se encerra em 1970, com a descoberta de que a área do horizonte de eventos é proporcional à matéria ou radiação que cai no buraco negro, levando à correlação entre essa área e a entropia e, posteriormente, à sugestão de Jacob Bekenstein sobre a perda de informação durante o colapso gravitacional. Segundo Hawking [3], a entropia do buraco negro seria então uma "medida da quantidade de informação que foi irreversivelmente perdida durante o colapso que formou o buraco negro" (p.34).

$\mathrm{Na}$ segunda palestra, Stephen dá destaque às suas próprias investigações, como as que levaram à conjectura

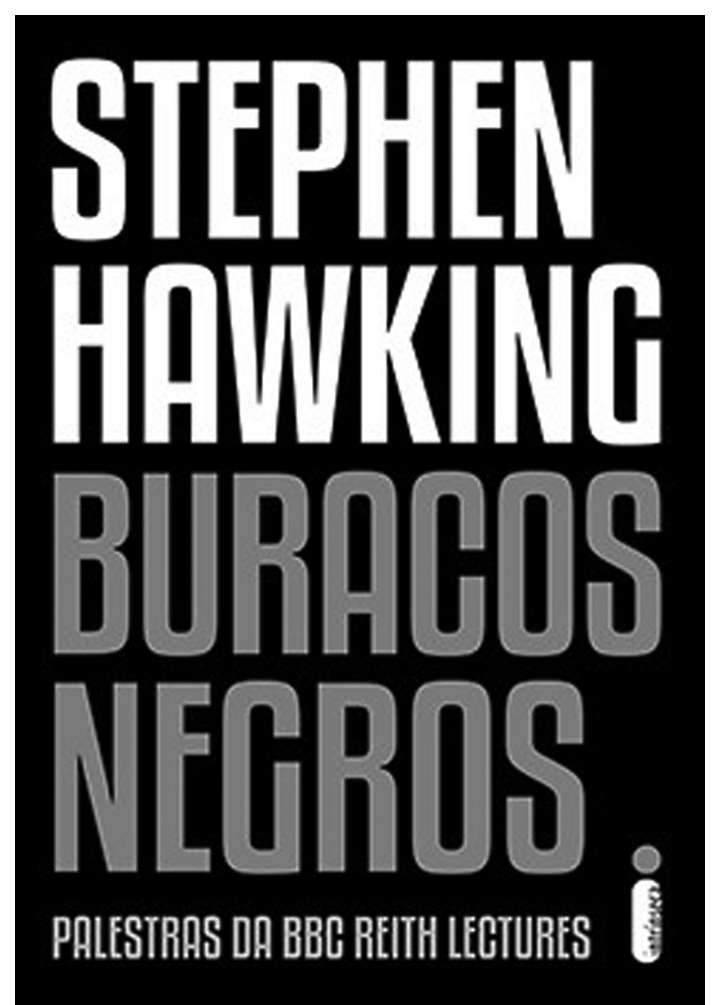

Figura 1: Capa da edição brasileira [3].

da existência da "radiação Hawking" no início dos anos 1970, assim como a proposta de que os buracos negros teriam uma temperatura proporcional à sua gravidade de superfície e inversamente proporcional à sua massa. Hawking destaca o valor que ele atribuiu às partículas virtuais para a ocorrência desses processos, e comenta sobre os esforços da comunidade científica para a detecção dessa radiação, em especial a possibilidade de criação de miniburacos negros em aceleradores de partículas. Jocosamente, ele brinca com a possibilidade de ganhar o Prêmio Nobel se tal radiação vier a ser detectada.

Ao final da segunda palestra, Hawking volta então ao tema da perda de informação em buracos negros, e comenta sobre um artigo de sua autoria, cujo resumo é reproduzido no apêndice do livro [9], no qual ele defende que a informação fica armazenada no horizonte de eventos. Sua fala se encerra com uma argumentação a respeito da possibilidade de buracos negros com rotação serem portais para outros universos.

A nosso ver, a leitura não traz grandes novidades ou insights para pesquisadores em cosmologia ou professores de física, mas seu caráter de introdução e divulgação permitiria sua incorporação em propostas de abordagem de temas da cosmologia no ensino médio. Nesse aspecto, acreditamos que o livro se revelaria como um "guia rápido" sobre o tema dos buracos negros, adequado a uma primeira abordagem nesse nível de ensino, podendo ser complementado por textos mais densos do próprio autor presentes em suas obras anteriores $[2,6]$. 


\section{Referências}

[1] K. Ferguson, Stephen Hawking: His Life and Work (Bantam Press, Londres, 2011), p. 186.

[2] S. Hawking, Uma Breve História do Tempo: Do Big Bang aos Buracos Negros (Rocco, Rio de Janeiro, 1988), $1^{\text {a }}$ ed.

[3] S. Hawking, Buracos Negros: Palestras da BBC Reith Lectures (Intrínseca, Rio de Janeiro, 2017), $1^{\mathrm{a}}$ ed., 64 p.

[4] BBC Radio 4, Prof. Stephen Hawking: The Reith Lectures (2016), disponível em http://www.bbc.co. uk/programmes/articles/1qCD6jwN3c6GSzY0SY7DYjH/ professor-stephen-hawking, acesso em 3/2/2017.

[5] BBC Radio 4, The Reith Lectures: Episodes (2017), disponível em http://www.bbc.co.uk/programmes/ b00729d9/episodes/guide, acesso em 3/2/2017.

[6] S. Hawking, O Universo Numa Casca de Noz (Mandarim, São Paulo, 2001), 1 $1^{\mathrm{a}}$ ed., 216 p.

[7] R. Oppenheimer and G. Volkoff, Physical Review 55, 455 (1939)

[8] R. Oppenheimer and H. Snyder, Physical Review 56, 455 (1939).

[9] S. Hawking, M. Perry and A. Strominger, Physical Review Letters 116, 231301 (2016). 